\title{
SISTEM INFORMASI PENDAFTARAN SELEKSI KERJA BERBASIS WEB PADA BKK (BURSA KERJA KHUSUS) TUNAS INSAN KARYA SMK NEGERI 2 BANYUMAS
}

\author{
${ }^{1)}$ Vembria Rose Handayani, ${ }^{2)}$ Ragil Wijianto, ${ }^{3)}$ Ari Anggoro \\ 1) Manajemen Informatika, AMIK BSI Purwokerto \\ vembria.vrh@bsi.ac.id \\ 2) Sistem Informasi, STMIK Nusa Mandiri Jakarta \\ ragil.rgw@nusamandiri.ac.id \\ 3) Manajemen Informatika, AMIK BSI Purwokerto \\ ari.anggoro1234@gmail.com
}

\begin{abstract}
BKK Tunas Insan Kaya has some shortcomings in supporting to serve the registrant from a great distance as well as from schools outside Banyumas. The current registration by filling out the form at the registration post and google drive, so the registrant often forget or do not know about the test schedule or announcement accepted or rejected by the company. Notifications via short messages SMS are sometimes ineffective applicants prefer to change the SIM card to get more internet quota. Making BKK Tunas Insan Kaya website can solve the distance problem, time and better information management. Following recruitment is as easy as pressing a button to bet he goal of this project. Applicant come not only from Banyumas district but also from outside Banyumas distric. This shows the function of BKK Tunas Insan Karya as an institution among active work in enforce it's duties. The membership fee can be transferred through the bank then the registrant upload the edvince through the member's space. Test carad and schedule selection can be downloaded in the member's room when it becomes member and pay the selection fee.
\end{abstract}

\section{Keywords: BKK Tunas Insan Karya, Information System Registration, Website}

\begin{abstract}
Abstrak - BKK Tunas Insan Kaya memiliki kesulitan untuk melayani Pendaftar dengan jarak yang jauh maupun dari sekolah di luar Banyumas. Pendaftaran yang dilakukan saat ini di lakukan melalui pengisian formulir di posko pendaftaran dan google drive. sehingga Pendaftar sering lupa atau tidak tahu mengenai jadwal tes maupun pengumuman diterima atau ditolak oleh Perusahaan. Pemberitahuan melalui pesan singkat SMS terkadang tidak efektif karena Pendaftar lebih memilih ganti kartu untuk mendapatkan kuota Internet yang banyak. Pembuatan website untuk BKK Tunas Insan Karya dapat mengatasi masalah jarak, waktu dan pengolahan informasi yang lebih baik. Mengikuti proses seleksi semudah menekan tombol menjadi tujuan Proyek ini. Pendaftar datang tidak hanya dari Kabupaten Banyumas tetapi juga dari Berbagai kota di luar Karsidenan Banyumas. Hal ini menujukan peningkatan Fungsi BKK Tunas Insan Karya sebagai lembaga antar kerja aktif dalam melakukan tugasnya. Iuran penyelenggaraan dapat di transfer melalui bank kemudian Pendaftar mengunggah bukti melalui ruang Member. Kartu ujian dan jadwal seleksi dapat diunduh diruang member apabila sudah menjadi member dan membayar iuran penyelenggaran seleksi.
\end{abstract}

\section{Kata Kunci: BKK Tunas Insan Karya, Sistem Informasi Pendaftaran, Website}

\section{A. PENDAHULUAN}

Pembuatan website saat ini menjadi hal yang umum bagi suatu lembaga yang ingin memudahkan akses informasi dan memberikan pelayanan untuk para pengguna jasa maupun barang produksi. Web yang resonsive juga menjadi tantangan karena pengguna internet sudah beralih ke mobile internet.

Pembuatan website didasarkan kebutuhan tersebut biasanya menuntut lebih pada kecepatan maka pemilihan hosting yang tepat dapat menangani masalah tersebut. Tampilan website juga menjadi hal yang di utamakan karena semakin bagus tampilan maka akan menarik semakin banyak pengunjung.
Pemilihan bahasa pemrograman yang tepat juga menjadi acuan pengembangan sistem pada waktu yang akan datang. Pemilihan perangkat lunak sebagai dasar sistem berjalan juga menjadi titik tentu pengembangan sistem yang nantinya akan menggunakan perangkat lunak baru atau masih dalam penyedia perangkat lunak yang sama. Misalkan sekarang menggunakan MySQL di masa depan akan menggunakan MySQL atau berganti ke yang lain Oracle misalkan.

Pembuatan website untuk BKK Tunas Insan Karya Menggunakan beberapa Bahasa Pemrograman untuk menghasilkan website yang stabil dan aman. Beberapa framework 
juga digunakan untuk membangun website BKK Tunas Insan Karya yaitu Codeigniter, dompdf atau phptopdf, bootstrap dan ckeditor.

Tidak tertinggal pula jQuery, ya ini merupakan sebuah framework yang berisi kumpulan fungsi-fungsi khusus javascript ini sangat membantu dalam pembuatan website karena sudah ada pustaka jQuery maka tidak perlu membuat ulang fungsi khusus javascript.

Aplikasi yang di gunakan untuk membuat website BKK Tunas Insan Karya yaitu NetBeans, CorelDraw X7, XAMPP dan beberapa perangkat lunak pendukung lainya yang fungsinya berbeda-beda. Masing-masing memiliki kelebihan dan kekurangan jika di bandingkan dengan aplikasi lain tapi menurut penulis ini yang paling baik. Bahasa Pemrograman yang di gunakan adalah PHP karena PHP tersedia gratis dan opensource server di internet juga pasti mendukung PHP maka PHP menjadi pilihan bahasa pemrograman yang terbaik menurut penulis. Codeigniter merupakan kerangka kerja yang cukup ringan dan tidak perlu composer tambahan untuk menjalankannya dan sintaknya mudah dipahami maka codeigniter menjadi framework pilihan penulis dan beberapa framework yang lain tinggal memanggil dan di gunakan.

\section{B. TINJAUAN PUSTAKA}

\section{Sistem}

Menurut Sutabri (2012:6) menerangkan bahwa Sistem pada dasarnya adalah sekelompok unsur yang erat hubungannya satu dengan yang lain, yang berfungsi bersamasama untuk mencapai tujuan tertentu.

\section{Informasi}

Menurut Sutabri (2012:22) menjelaskan bahwa Informasi adalah data yang diklasifikasikan atau diolah atau diinterpretasikan untuk digunakan dalam proses pengambilan keputusan.

\section{Sistem Informasi}

Menurut Sutabri (2012:38) menjelaskan bahwa Sistem Informasi adalah suatu sistem di dalam suatu organisasi yang mempertemukan kebutuhan pengolahan transaksi harian yang mendukung fungsi operasi organisasi bersifat manajerial dengan kegiatan strategi dari suatu organisasi untuk dapat menyediakan laporanlaporan yang diperlukan oleh pihak luar tertentu.

\section{Rekrutmen}

Menurut Triyono (2012:43) beliau mendefinisikan yaitu Berdasarkan pengertianpengertian tersebut maka rekrutmen dapat di definisikan sebagai proses mencari, menemukan dan menarik para pelamar untuk dipekerjakan dalam dan oleh suatu organisasi sebagai langkah awal untuk mendapatkan calon karyawan yang setepat-tepatnya untuk menduduki suatu pekerjaan.

\section{Internet}

Menurut Ahmadi dan Hermawan (2013:68) menggambarkan bahwa Internet merupakan komunikasi jaringan global yang menghubungkan seluruh komputer di dunia meskipun berbeda sistem operasi dan mesin. Sedangkan menurut Yuhefizar (2008:1) menjelaskan bahwa Internet adalah rangkaian hubungan jaringan komputer yang dapat diakses secara umum di seluruh dunia, yang mengirimkan data dalam bentuk paket data berdasarkan standar IP.

\section{Website}

Menurut

Puspitosari

(2010:1) mengemukakan bahwa Website adalah halaman informasi yang disediakan melalui jalur internal sehingga bisa diakses di seluruh dunia, selama terkoneksi dengan jaringan internet.

\section{Web Browser}

Menurut Abdulloh (2016:5) menggambarkan bahwa Web browser Digunakan untuk menampilkan hasil website yang telah dibuat. Web browser yang paling sering digunakan, di antaranya Mozilla Firefox, Google Chrome, Internet Explorer, Opera, dan Safari.

\section{Web Server}

Menurut Arief (2011:19) memberikan penjelasan bahwa Web Server adalah program aplikasi yang memiliki fungsi sebagai tempat menyimpan dokumen-dokumen web.

\section{Web Hosting}

Menurut Ahmadi dan Hermawan (2013:53) memberikan definisi Web Hosting adalah salah satu bentuk layanan jasa penyewaan tempat di internet yang memungkinkan perorangan ataupun organisasi menampilkan layanan jasa atau produknya di web atau situs internet.

\section{HTML}

Menurut Abdulloh (2016:2) menjelaskan tentang HTML singkatan dari Hyper Text Markup Language, yaitu skrip yang berupa tagtag untuk membuat dan mengatur struktur website.

\section{PHP}

Menurut Abdulloh (2016:3) memberikan gambaran tentang PHP singkatan dari Hypertext Preprocessor yang merupakan 
server-side programming, yaitu bahasa pemrograman yang diproses di sisi server.

\section{CSS}

Menurut Abdulloh (2016:2) menjelaskan tentang bahwa CSS singkatan dari Cascading Style Sheets, yaitu skrip yang digunakan untuk mengatur desain website.

\section{Java Script}

Menurut Abdulloh (2016:3) memaparkan tentang Peran javascript dalam membuat website adalah memberikan efek animasi yang menarik dan interaktif dalam penanganan event yang dilakukan oleh pengguna website.

\section{4.jQuery}

Menurut Abdulloh (2016:147) menjelaskan jika jQuery merupakan salah satu java script library, yaitu kumpulan fungsi java script siap pakai, sehingga mempermudah dan mempercepat kita dalam membuat kode java script.

\section{Software}

Menurut Vicky (2008:45) menjelaskan bahwa Software adalah sekumpulan data elektronik yang disimpan dan diatur oleh komputer, data elektronik yang disimpan oleh komputer itu dapat berupa program atau instruksi yang akan menjalankan suatu perintah.

\section{XAMPP}

Menurut Wardana (2015:4) dalam bukunya menerangkan bahwa XAMPP adalah paket software yang di dalamnya sudah terkandung Web Server Apache, database MySQL, dan PHP interpreter.

\section{NetBeans}

Menurut Faizal dan Irnawati (2015:5) menerangkan NetBeans IDE adalah sebuah lingkungan pengembangan sebuah kakas untuk memrogram menulis, mengompilasi, mencari kesalahan dan menyebarkan program.

\section{CoreIDRAW}

Menurut Madcoms (2012:3) menerangkan bahwa CorelDRAW adalah aplikasi desain grafis yang berguna untuk membuat desain vektor, logo, dan layout halaman.

\section{Framework}

$\mathrm{Di}$ kutip dari www.malasngoding.com "Framework adalah kumpulan intruksi-intruksi yang di kumpulkan dalam class dan functionfunction dengan fungsi masing-masing untuk memudahkan developer dalam pemanggilannya tanpa harus menuliskan syntax program yang sama berulang-ulang. Hal ini memiliki kegunaan untuk menghemat waktu dan mencegah penulisan syntax secara berulang-ulang agar terciptanya source code yang bersih dan terstruktur." (Diki Alfarabi Hadi ,12 Januari 2016 http://www.malasngoding.com/pengertian-dancara-menggunakan-codeigniter/, diakses tanggal 07 Mei 2017).

\section{Codeigniter}

Supono dan Putratama (2016:109) Codelgniter adalah aplikasi open source berupa framework dengan model MVC (Model, View, Controller) untuk membangun website dinamis dengan menggunakan PHP"

\section{Bootstrap}

Menurut Abdulloh (2016:157) Bootstrap merupakan salah satu framework CSS yang sangat populer di kalangan pecinta pemrograman website. Dengan menggunakan bootstrap, proses desain website tidak dibuat dari nol, sehingga proses desain website lebih cepat dan mudah.

\section{CKEditor}

Di kutip dari situs www.ilmu.org "CKEditor adalah teks editor yang digunakan di lingkungan web. CKEditor adalah sebuah WYSIWYG editor, yang berarti teks yang diedit akan sama dengan yang akan tampil." (Angga Panugali, www.ilmu.org, diakses tanggal $19 \mathrm{Mei}$ 2017).

\section{DataTable}

Menurut Purbadian (2016:29) menerangkan demikian Menurut penulis data tables itu adalah sebuah plugin jQuery yang sangat powerful, kenapa demikian? Di samping mudah untuk mengimplementasikannya, plugin jQuery data tables sudah terintegrasi dengan search form, page initation, serta dengan jumlah data yang ditampilkan. Dengan adanya fitur-fitur itu tentu saja kita dapat menghemat waktu dalam membangun sebuah aplikasi web.

\section{Php to Pdf}

Dikutip dari situs resmi php to pdf "The simplest and most reliable PHP to PDF generation. Just include a single php file." (Php to Pdf, http://phptopdf.com, diakses tanggal 09 Mei 2017).

\section{Basis Data (Database)}

Menurut Sutabri (2012:39) Basis data (database) merupakan kumpulan data yang saling berkaitan dan berhubungan satu dengan yang lainnya, tersimpan di perangkat keras 
komputer dan perangkat lunak digunakan untuk memanipulasinya.

Menurut Rosa dan Shalahuddin (2013:43) menjelaskan bahwa Basis data adalah sistem terkomputerisasi yang tujuan utamanya adalah memelihara data yang sudah diolah atau informasi dan membuat informasi tersedia saat dibutuhkan. Pada intinya basis data adalah media untuk menyimpan data agar dapat diakses dengan mudah dan cepat.

\section{MySQL}

Menurut Faizal dan Irnawati (2015:4) mendefinisikan MySQL merupakan perangkat lunak sistem manajemen berbasis data SQL (bahasa Inggris : database management system) atau DBMS yang multithread dan multiuser, dengan sekitar 6 (enam) juta instalasi di seluruh dunia.

\section{PhpMyAdmin}

Menurut Abdulloh (2016:4) PhpMyAdmin merupakan aplikasi berbasis web yang digunakan untuk membuat database MySQL sebagai tempat untuk menyimpan data-data website.

\section{SLDC}

Menurut Rosa dan Shalahuddin (2013:28) secara umum Tahapan dalam waterfall model atau SDLC meliputi tahap analisis, desain, pembuatan kode program, pengujian dan tahap pendukung (support) atau pemeliharaan (maintenance).

\section{Struktur Navigasi}

Menurut Andriansyah (2016:611) menjelaskan Struktur navigasi dapat diartikan sebagai alur dari suatu program yang menggambarkan hubungan antar area yang berbeda sehingga memudahkan proses pengorganisasian seluruh elemen website.

\section{ERD}

Menurut Rosa dan Shalahuddin (2013:53) "Entity Relationship Diagram (ERD) Merupakan bentuk paling awal dalam melakukan perancangan basis data relasional. Jika menggunakan OODBMS maka perancangan ERD tidak perlu dilakukan".

\section{LRS}

Menurut Tabrani (2014:35) memberikan gambaran LRS adalah Logical Record Structure dibentuk dengan nomor dari tipe record. Beberapa tipe record digambarkan oleh kotak empat persegi panjang dan dengan nama yang unik. Perbedaan LRS dengan E-R diagram adalah nama tipe record berada diluar kotak field tipe record di tempatkan.

\section{Black Box Testing}

Menurut Rosa dan Shalahuddin (2013:275) mendefinisikan Black Box Testing (pengujian kotak hitam) yaitu menguji perangkat lunak dari segi spesifikasi fungsional tanpa menguji desain dan kode program. Pengujian dimaksud untuk mengetahui apakah fungsi-fungsi, masukan, dan keluaran dari perangkat lunak sesuai dengan spesifikasi yang dibutuhkan.

\section{METODE PENELITIAN}

Metode yang digunakan pada penelitian ini yaitu:

1. Studi litelatur, yaitu suatu metode untuk mendapatkan informasi dan melakukan pengumpulan data dengan membaca dan mempelajari berbagai litelatur-litelatur antara lain bersumber dari buku, jurnal,modul, refrensi internet, dan lain-lain yang mana sumber-sumber tersebut berhubungan dengan masalah yang diangkat sehingga dapat membantu dalam meyelesaikan permasalahan yang ada.

2. Metode pengembangan perangkat lunak menggunakan metode SDLC (Software Development Life Cycle) dengan model Waterfall yaitu: analisa, rancangan, pengkodean, dan implementasi.

\section{HASIL DAN PEMBAHASAN}

\section{Tinjauan Perusahaan}

a) Sejarah

BKK Tunas Insan Karya adalah lembaga yang bergerak dibidang penyaluran tenaga kerja sejak tahun 2009. Didirikan oleh Bapak Slamet Kustikno, S.Pd. Saat itu SMKN 2 Banyumas masih dikepalai oleh Bapak Slamet Sartono, SP, M.Pd. Ketika itu masih belum ada Bursa Kerja yang menampung lulusan untuk bekerja di Perusahaan maupun di tempatkan di luar negeri. Perusahaan yang pertama kali menandatangani kerja sama adalah PT. Sukofindo yang sekarang masih menjadi mitra BKK Tunas Insan Karya. Seiring berjalanya waktu semakin banyak Perusahaan yang bergabung dengan BKK Tunas Insan Karya di antaranya PT AHM (Astra Honda Motor), PT ADM (Astra Daihatsu Motor), PT JIAEC, PT ATI dan Perusahaan lain yang terdaftar. Surat Keputusan BKK Tunas Insan Karya telah diganti beberapa kali, hal ini terjadi karena Peraturan Pemerintah yang mewajibkan Agar Bursa Kerja Khusus membuat surat izin untuk melakukan kegiatan Antar Kerja atau biasa disebut penyaluran tenaga kerja. 
b) Struktur Organisasi

Bentuk struktur organisasi yang dimiliki BKK Tunas Insan Karya:

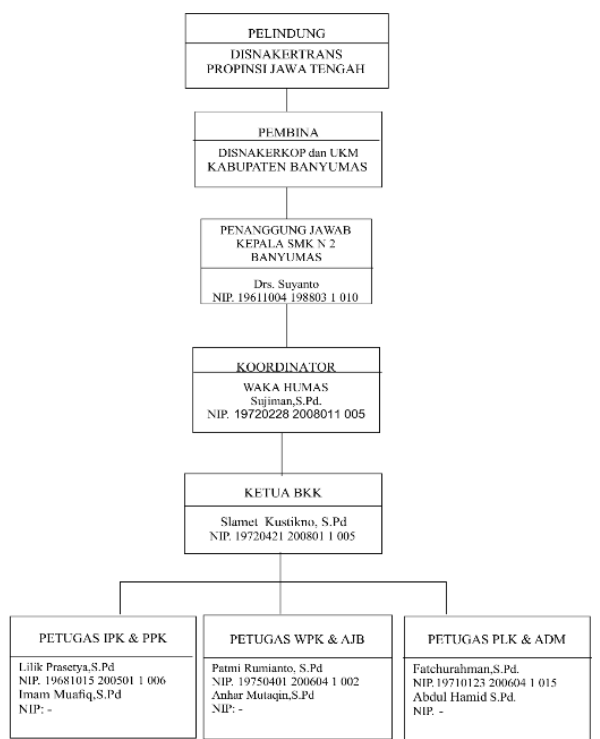

Sumber: Ketua BKK Tunas Insan Karya

Gambar 1. Struktur Organisasi

\section{Analisis Kebutuhan}

Adalah analisa kebutuhan pengguna dan analisa kebutuhan sistem yang saling berinteraksi dalam lingkungan sistem, yaitu:

a) Kebutuhan Fungsional (Functional

Requirement)

1) Website harus dapat melakukan

penyaringan user.

(a) Member

Pengunjung yang telah terdaftar sebagai member dapat melakukan login dengan memasukan email dan password dengan benar untuk dapat melakukan login di halaman login member.

(b) Pegawai

Pegawai dapat melakukan login pegawai untuk masuk ke halaman pegawai dengan memasukan username dan password dan melakukan konfirmasi pembayaran.

(c) Admin

Admin dapat melakukan login untuk dapat masuk ke halaman admin dengan menginputkan username dan password dengan benar agar dapat memanipulasi data.

2) Website harus dapat menyajikan semua kebutuhan user.

(a) Beranda, berisi gambaran profil BKK Tunas Insan Karya. (b) Member, berisi halaman untuk mendaftar sebagai member dan cara pendaftarannya.

(c) Bantuan, berisi halaman yang menjelaskan permasalahan yang umum terjadi untuk member baru ataupun pengunjung baru.

(d) Teman, berisi data member yang telah terdaftar di basis data dapat di lihat oleh teman atau pengunjung yang belum mendaftar.

(e) Hubungi Admin, berisi formulir untuk mengirim informasi kepada admin.

(f) Lowongan, berisi informasi lowongan kerja yang di input oleh admin.

(g) Ruang Member, adalah laman bagi pengunjung yang sudah terdaftar sebagai member di BKK Tunas Insan Karya.

(h) Ruang Pegawai, adalah laman yang di gunakan untuk konfirmasi pembayaran iuran penylengaraan.

3) Website harus dapat melakukan manajemen data, seperti input data, edit data, ubah data, dan hapus data yang terdapat pada halaman utama masing-masing user.

(a) Pengunjung Terdaftar atau Member

(1) Member dapat mengubah biodata di halaman akun.

(2) Member dapat mengikuti seleksi kerja.

(3) Member dapat membatalkan untuk mengikuti seleksi.

(4) Member dapat melihat informasi lowongan.

(5) Member dapat melihat jadwal seleksi.

(6) Member dapat melakukan ujian seleksi secara online.

(7) Member dapat melihat hasil seleksi.

(b) Pegawai

(1) Pegawai dapat melakukan konfirmasi pembayaran iuran penyelenggaraan.

(2) Pegawai dapat melihat data pelamar yang mengikuti seleksi.

(3) Pegawai dapat menambahkan pengumuman untuk member.

(c) Admin

(1) Admin dapat mengelola informasi yang ada di halaman utama web seperti beranda, bantuan dan lowongan. 
(2) Admin dapat menambah, mengedit dan menghapus data lowongan, soal ujian jadwal ujian, data yang dapat di edit oleh admin adalah data yang berkaitan dengan proses berjalanya seleksi buka untuk keamanan website.

(3) Admin dapat menulis pengumuman kepada seluruh member.

(4) Admin dapat mencetak data tertentu seperti hasil seleksi berupa file Ms. Excel dan mengunduhnya.

4) Website harus bisa menyediakan fasilitas interaktif antara manajemen (admin) dan pengunjung terdaftar.

(a) Hubungi Admin, merupakan fasilitas yang disediakan bagi pengunjung untuk meninggalkan pesan yang berkaitan dengan BKK Tunas Insan Karya.

(b) Formulir keluhan di halaman member merupakan fasilitas yang disediakan bagi pengunjung untuk meninggalkan pesan yang berkaitan dengan, kesalahan maupun keluhan yang dialami oleh member pengguna website BKK Tunas Insan Karya.

(c) Admin berhak mengelola informasi saran, keluhan serta masukan dari pengguna website.

5) Website harus dapat membuat atau menciptakan output, yaitu cetak bukti pendaftaran dan kartu ujian.

b) Kebutuhan Non Fungsional

Adalah kebutuhan yang berisi tentang pendukung dari pembutan website.

1) Kebutuhan Perangkat Keras (Hardware)

Agar website dapat berjalan dan memaksimalkan semua fungsinya, maka harus didukung oleh perangkat keras yang baik. Minimal kebutuhan hardware tersebut adalah sebagai berikut:

(a) Komputer atau Laptop (1) Processor
(TM) 2 Duo
(2) $R A M$
(3) Harddisk
: Intel (R) Core
(4) Monitor :
: $2 \mathrm{~GB}$
: $300 \mathrm{~GB}$ $1366 \times 768$
(5) Mouse : Touchpad/Mouse
(6) Keyboard : Standard $P S / 2$

(b) Ponsel atau Smartphone
(1) Processor : Qualcomm Snapdragon (Semua Versi)

(2) $R A M$ : $512 \mathrm{MB}$

(3) Memori : $1 \mathrm{~GB}$

(4) Monitor : Resolusi layar $480 \times 720$ (4 inches)

(5) OS : Semua Sistem operasi yang mendukung internet

2) Kebutuhan Perangkat Lunak (Software)

(a) Sistem Operasi: Windows 10 Enterprise

(b) Program Desain: Corel Draw X7

(c) Aplikasi Pendukung: Adobe Photoshop CS 6

(d) Web server: Apache

(e) Web browser: Opera

(f) Bahasa Pemrograman: PHP, HTML, CSS, Javascript, jQuery

(g) Database: MySQL

\section{Perancangan Perangkat Lunak}

Adalah gambaran umum mengenai website BKK Tunas Insan Karya. Website yang dibuat memiliki 3 bagian tampilan rancangan, yaitu rancangan tampilan visitor (pengunjung), rancangan tampilan pengunjung terdaftar atau member dan rancangan tampilan admin.

a) Halaman Pengunjung

Halaman ini merupakan halaman yang pertama kali muncul saat pengunjung membuka web BKK Tunas Insan Karya.

Contoh rancangan untuk halaman pengunjung bagian beranda:

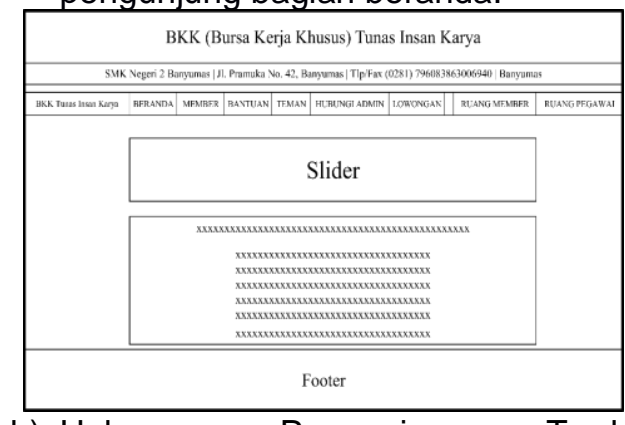

b) Halaman Pengunjung Terdaftar (Member)

Pengamanan untuk hak akses ke dalam basis data member dilakukan dengan memasukkan sesuatu yang diketahui oleh pemilik akun yaitu user dan password.

Contoh rancangan halaman beranda pada ruang member: 


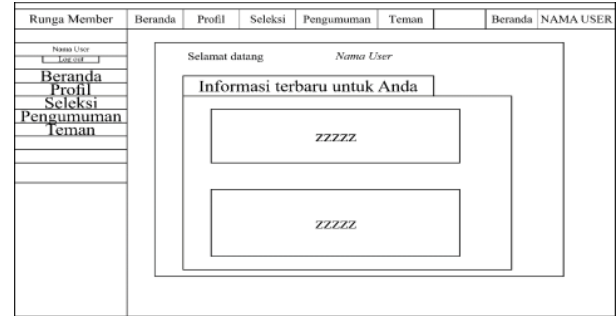

c) Halaman Pegawaai

Pegawai harus memasukan user dan password yang sudah di input sebelumnya oleh admin untuk akses data.

Contoh rancangan halaman pendaftaran di ruang pegawai:

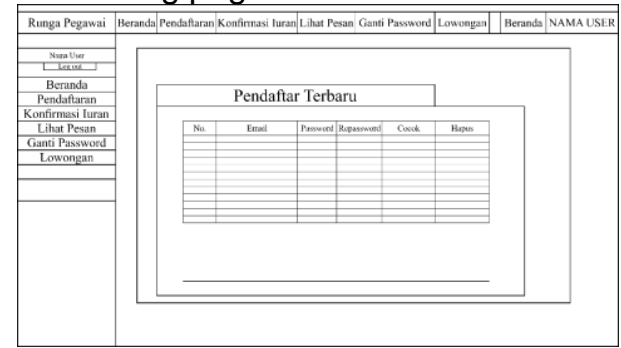

d) Halaman Administrator

Admin harus masuk terlebih dahulu di halaman login dengan sesuatu yang diketahui yaitu nama pengguna dan kata sandi.

Contoh rancangan halaman beranda di ruang Admin atau Super User:

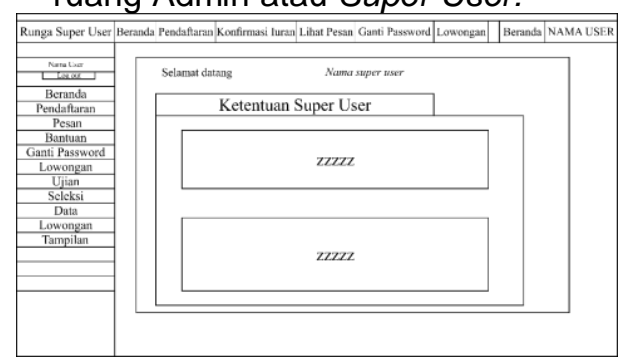

\section{Implementasi dan Pengujian Unit}

Implementasi dan pengujian unit sebagai langkah realisasi dan evaluasi dari perangkat lunak yang dibuat.

a) Implementasi Antarmuka

1) Hasil penerapan dari rancangan antarmuka beranda untuk umum:

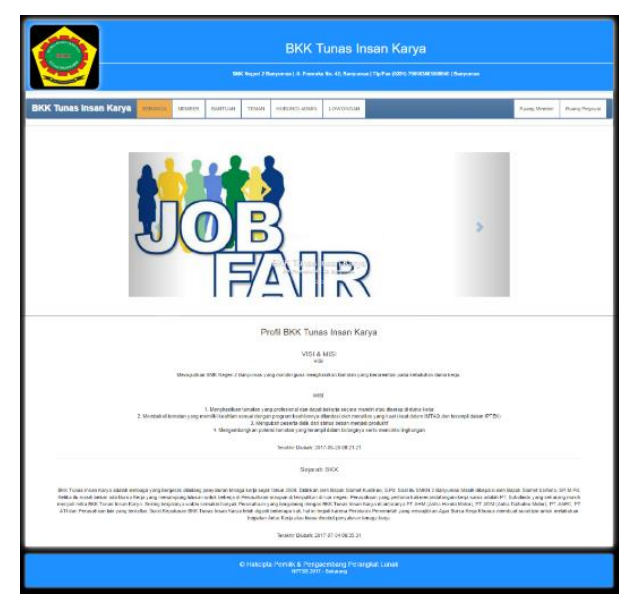

2) Hasil penerapan dari rancangan antarmuka informasi lowongan di ruang member:

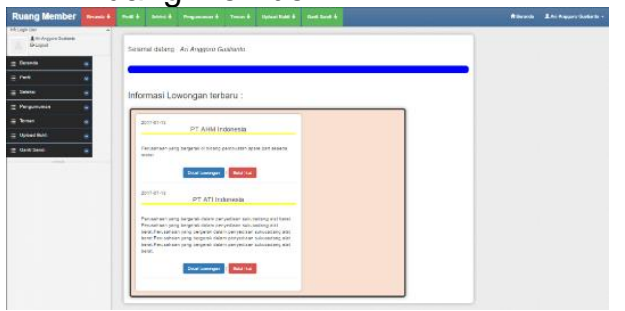

3) Hasil penerapan dari rancangan antarmuka informasi pendaftaran di ruang pegawai:

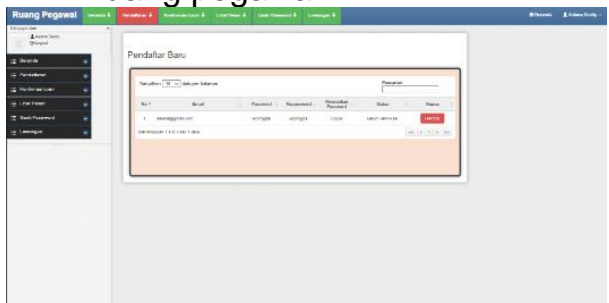

4) Hasil penerapan dari rancangan antarmuka sebelumnya halaman beranda untuk admin:

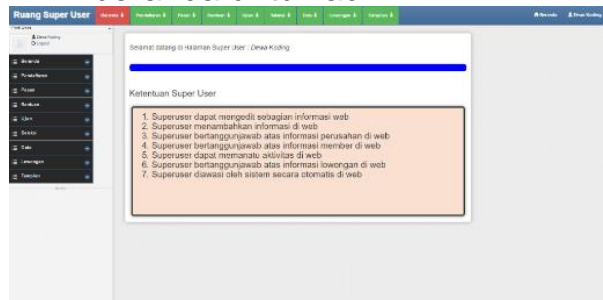

b) Spesifikasi Sistem Komputer

Merupakan pendukung dari aplikasi atau program sistem informasi berbasis web yang sangat penting. Spesifikasi sistem komputer yang digunakan meliputi:

1) Spesifikasi Perangkat Keras Perangkat keras yang dianjurkan untuk server website adalah:
(a) Prosesor minimal 1.7 Gigahertz ber-inti ganda.
(b) RAM minimal 2 Gigabyte.
(c) Harddisk minimal 320 Gigabyte.
(d) Bandwidth kecepatan minimal 2 
Megabit per second.

Perangkat keras desktop, laptop atau netbook yang dianjurkan untuk client adalah:

(a) Prosesor minimal 1 Gigahertz.

(b) Memori minimal 512 Megabyte.

(c) Harddisk minimal 4 Gigabyte.

(d) Koneksi dengan bandwidth minimal 256 Kilobit per second.

(e) Perangkat keyboard 101 key.

(f) Perangkat monitor minimal resolusi 800 piksel, lebar 10 inch.

2) Spesifikasi Perangkat Lunak Perangkat lunak yang dibutuhkan untuk server website adalah:
(a) Sistem Operasi Windows.
(b) Apache Web Server
(c) MySQL Server.
(d) PHP 5.6
(e) PhpMyAdmin.

Sedangkan perangkat lunak yang dianjurkan untuk client adalah:

(a) Sistem Operasi UNIX (Linux, BSD, Mac), atau Windows.

(b) Aplikasi web browser terkini seperti Mozilla Firefox, Google Chrome atau Opera.

5. Pengujian terhadap program yang dibuat menggunakan metode black box testing agar fokus terhadap masukan dan keluaran program.

\section{E. KESIMPULAN DAN SARAN}

1. Kesimpulan

Berdasarkan uraian yang telah dibahas pada bab-bab sebelumnya serta hasil rangkaian pengujian terhadap sistem yang dibangun dengan mengambil dan menganalisa data-data yang diperoleh dari website BKK Tunas Insan Karya. Maka dapat diambil beberapa kesimpulan sebagai berikut:

a) Sebelum adanya sistem pendaftaran kerja berbasis web, BKK Tunas Insan Karya melayani Pendaftar secara manual, sehingga keterbatasan waktu dan jarak tempuh menuju BKK Tunas Insan Karya Menjadi masalah. Sistem Informasi Pendaftaran Kerja untuk BKK Tunas Insan Karya dirancang untuk menangani masalah tersebut sehingga BKK Tunas Insan Karya dapat melayani Pendaftar lebih cepat.

b) Sistem Informasi Pendaftaran berbasis web untuk BKK Tunas Insan Karya dilengkapi dengan sistem memberisasi, sehingga pengguna web tidak perlu mengisikan data formulir berulang karena data diambil dari Profil yang telah diisi oleh member.

c) Sistem Informasi Pendaftaran berbasis web untuk BKK Tunas Insan Karya memberikan informasi kepada member dengan akurat, Pengelola BKK Tunas Insan Karya dapat mengatur informasi serta pendaftar dapat melakukan pendaftaran melalui smartphone.

d) Web untuk BKK Tunas Insan Karya dibuat responsive sehingga mudah dan ringan saat di kunjungi melali smartphone.

\section{Saran}

Dari pembahasan sebelumnya, diberikan saran-saran dengan tujuan untuk memaksimalkan penggunaan sistem. Berikut ini adalah saran-saran yang dapat diberikan:

a) Hendaknya setiap tahun Admin melakukan pembersihan file sampah pada hosting karena file yang tidak diperlukan akan menumpuk seiring berjalanya waktu serta melakukan perpanjangan atau melakukan pembayaran kembali hosting agar website tetap berjalan.

b) Hendaknya melakukan pelatihan menggunakan website kepada Pegawai di BKK Tunas Insan Kaya untuk mengelola informasi.

\section{DAFTAR PUSTAKA}

[1] Abdulloh, Rohi. 2016. Easy \& Simple Web Programing. Jakarta: PT Elex Media Komputindo.

[2] Andriansyah, Doni. 2016. Sistem Informasi Pendaftaran Event Dengan PHP Untuk Panduan Skripsi. Cirebon: CV. ASFA Solution.

[3] Purbadian, Yenda. 2016. Framework Codeigniter 3 Membangun Aplikasi Penggajian Untuk Panduan Sekripsi. Cirebon: CV. ASFA Solution, Software Development, IT \& Publishing.

[4] Faizal, Edi dan Irnawati. 2015. Proram Java Web (JSP, JSTL, \& SERVERLET) tentang Pembuatan Sistem Informasi Klinik Diimplementasikan Dengan Netbeans IDE 7.2 dan MySQL.

[5] Triyono, Ayon. 2012. Pradigma Baru Manajemen Sumberdaya Manusia. Jakarta: ORYZA.

[6] MADCOMS. 2012. Mahir Dalam 7 Hari CorelDRAW 6. Yogyakarta: CV Andi Offset.

[7] Sutabri, Tata. 2012. Analisis sistem Informasi Oleh: Tata Sutabri. Yogyakarta: CV Andi Offset. 
[8] Salahudin, M dan Rosa. 2013. Rekayasa Perangkat Lunak Terstruktur Berorientasi Objek. Bandung: Informatika Bandung.

[9] Winarno, Edy, Ali Zaki dan SmitDev Comunity. 2013. Buku Sakti Pemrograman PHP. Jakarta: PT. Gramedia.

[10] Pawirosumarto, Suharno. 2008. Aplikasi Komputer. Jakarta: Mitra Wacana Media.

[11] Spurlock, Jake. 2013. Bootstrap. Sbastopol: O'Reilly Media.

[12] Sutisna, Dadan. 2008. 7 Langkah Mudah Menjadi Web Master. Jakarta Selatan: Mediakita.

[13] Zaki, Ali dan SmitDev Comunity. 2008. 36 Menit Belajar Komputer PHP dan MySQL. Jakarta: PT. Gramedia.

[14] Kun, Toni. 2010. Membuat Website Canggih dengan jQuery untuk Pemula.

[15] Heflfinger, Dafid R. 2008. Java EE Development with Netbeans 8. Brimingham: Packt Publishing.

[16] Redaksi Kawan Pustaka. 2008. Pintar 256 Software Computer. Jakarta Selatan: PT Kawan Pustaka.

[17] Anhar. 2010. Panduan mengusai PHP \& MySQL Secara Otodidak. Jakarta Selatan: Mediakita. 